\title{
El Plan Jacobeo 2021 confirma al Camino de Santiago como referente de las intervenciones en el patrimonio cultural
}

\begin{abstract}
Castilla y León cuenta con ocho bienes inscritos en la Lista de Patrimonio Mundial y dispone de más de dos mil bienes de interés cultural (BIC), que se reparten en unos 750 municipios de los 2.248 que existen. Desde hace décadas la administración está comprometida en la planificación ambiciosa del estudio y documentación de este patrimonio cultural, en su conservación preventiva e igualmente en los trabajos necesarios para su mantenimiento efectivo. El recientemente aprobado Plan Jacobeo 2021 ambiciona poner al día la gestión de los caminos a Santiago en los ámbitos patrimonial, de investigación y conocimiento, gestión, información, didáctico, social, cultural, de mantenimiento y modernización de las infraestructuras y los servicios.
\end{abstract}

Gumersindo Bueno Benito | Dirección General de Patrimonio Cultural, Consejería de Cultura y Turismo, Junta de Castilla y León

Url de la contribución <www.iaph.es/revistaph/index.php/revistaph/article/view/4544>

Castilla y León es Camino. La tradición y la historia se han confabulado para que por el Camino Francés afluya gran parte de la peregrinación de los caminos jacobeos que surcan nuestra región. Los peregrinos han hecho de esta ruta la predilecta, animando, desde 1993 con intensidad inusitada, un paisaje repleto de recursos patrimoniales. Si bien este territorio, como el conjunto de la Península, no era en absoluto ajeno a lo que acontecía en Europa desde tiempos prehistóricos, puede decirse que el Camino, surgido del hallazgo del sepulcro del Apóstol Santiago a principios del siglo IX, abrió de par en par las altas puertas del Pirineo y extendió una vía de conexión directa entre Castilla y León y el corazón de Europa.

El Camino de Santiago fue declarado en 1987 por el Consejo de Europa como primer itinerario cultural europeo e inscrito en la Lista de Patrimonio de la Humanidad en 1993, adquiriendo en 2004 la categoría de gran itinerario cultural europeo. Este reconocimiento de los valores del Camino Francés nos da la fuerza necesaria para servirnos del patrimonio cultural como herramienta imprescindible frente a la despoblación, e incluso como herramienta de repoblación.

Ahora bien, sostener la conservación y la gestión de los recursos patrimoniales para ponerlos a disposición de la sociedad requiere planificación. De un lado, el Plan PAHIS
2020 del Patrimonio Cultural de Castilla y León prevé la definición de los criterios de planificación, prioridades, pautas para la elaboración de proyectos y procedimientos y técnicas de intervención en los bienes culturales, cualquiera que sea su tipología. De otro lado, la búsqueda de la sostenibilidad en la gestión pública del patrimonio cultural se apoya en un principio global de concertación y corresponsabilidad en la investigación, desarrollo e innovación sobre los bienes y servicios del patrimonio cultural. Se otorga además especial atención a las prioridades de conservación, a los periodos históricos menos atendidos y a los usos posteriores del bien. Igualmente, la colaboración de acciones con otras instituciones forma parte de los criterios de priorización de cara a la intervención en los bienes, su sostenibilidad y proyección social.

Estos criterios y propuestas coinciden con el recientemente aprobado Plan Jacobeo 2021 de Castilla y León, que ambiciona poner al día la gestión de los caminos a Santiago en los ámbitos patrimonial, de investigación y conocimiento, gestión, información, didáctico, social, cultural, de mantenimiento y modernización de las infraestructuras y los servicios. Con la mirada puesta en la celebración del próximo año Jacobeo en 2021, el programa Hitos Camino tiene como objetivo la protección de bienes patrimoniales relevantes de los caminos a Santiago por Castilla y León, mediante intervenciones 


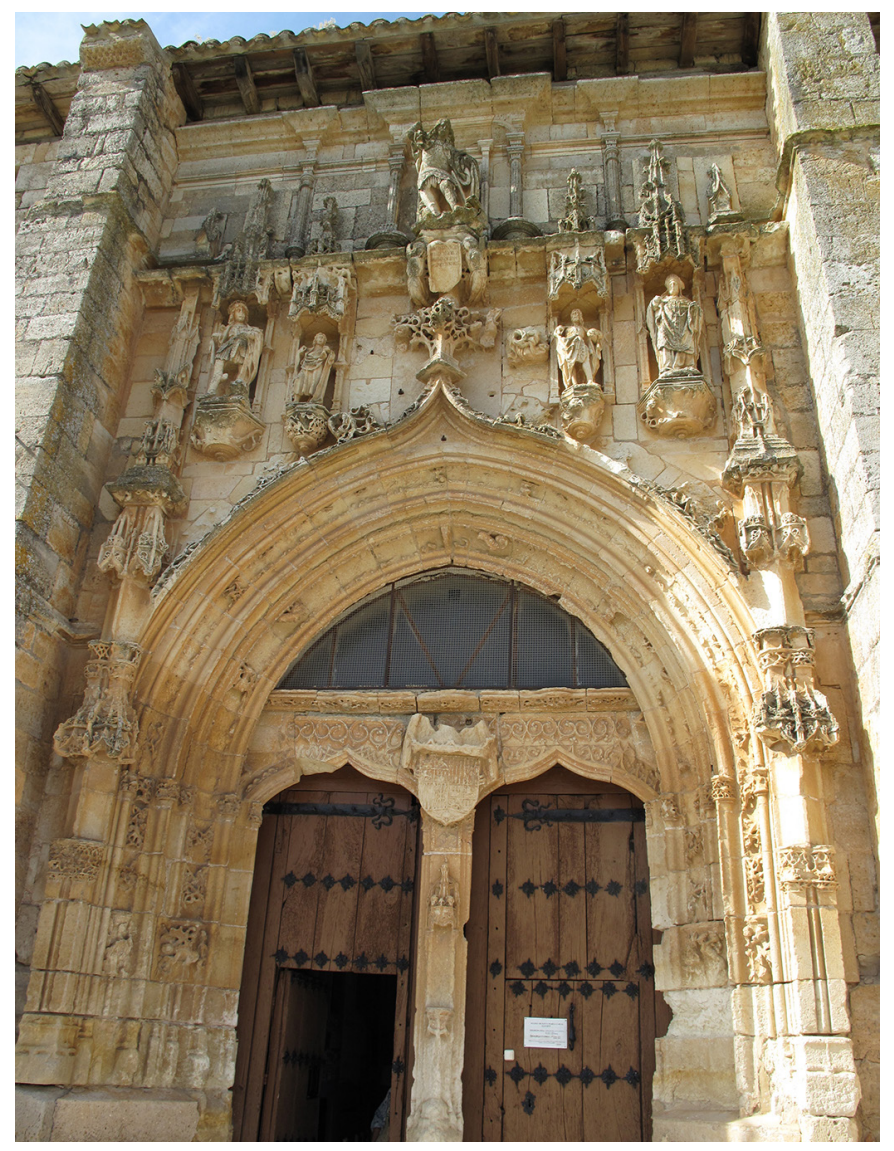

Santa María la Real de Sasamón

específicas de conservación, restauración y puesta en valor, todo ello considerando que los elementos históricos que jalonan los caminos a Santiago caracterizan de manera singular los itinerarios $y$, particularmente, lo que estos representan.

Así, en el periodo 2015-2018, se han realizado 23 intervenciones de restauración que han supuesto una inversión de alrededor 5.300 .000 euros y en los dos próximos años está previsto desarrollar otras 10 con un presupuesto próximo a 2.000.000 de euros, destacando entre ellas las que se han programado en el castillo de Cornatel y Santa María de Vizbayo en León o en la iglesia de Santa María la Real en Sasamón (Burgos).

Entre las actuaciones de restauración realizadas en bienes de especial consideración, cabe destacar la desarrollada sobre el conjunto escultórico del trasaltar de la

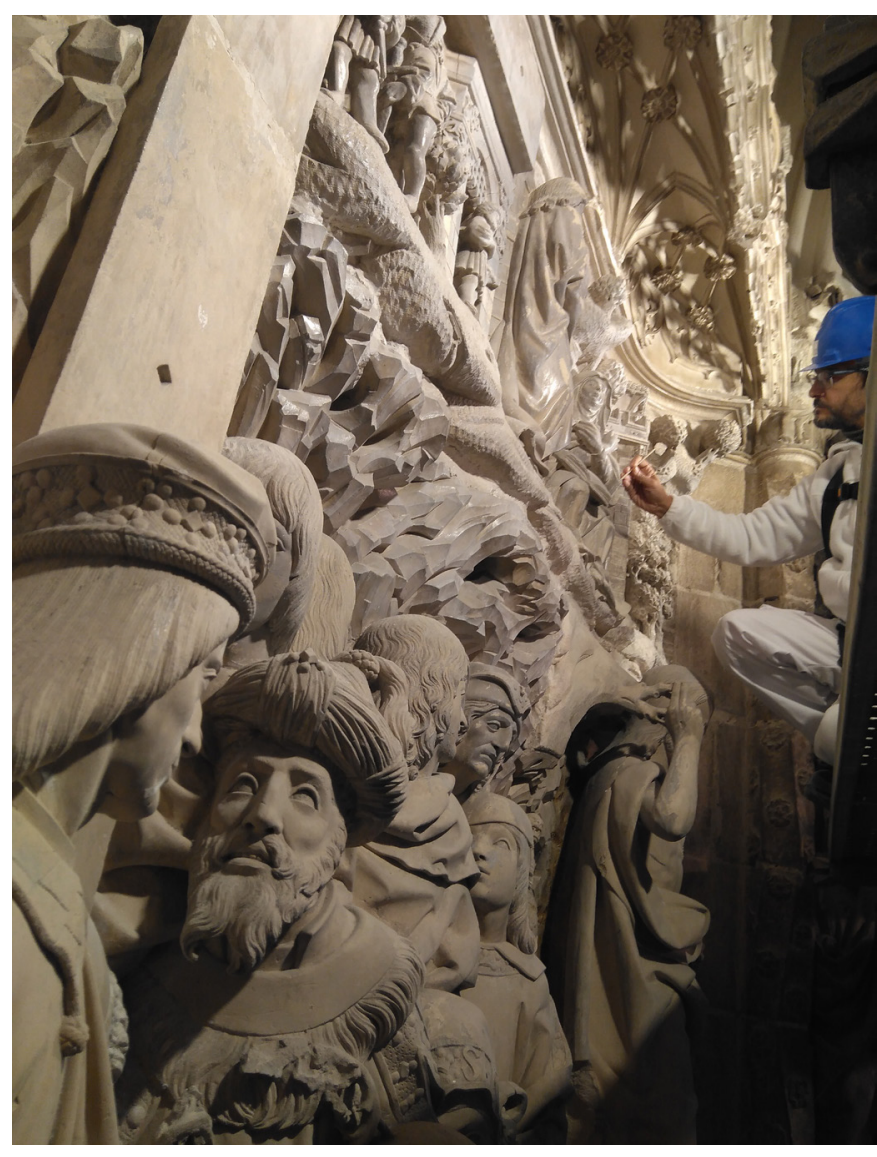

Trasaltar de la Catedral de Burgos. Proceso de limpieza relieves

Catedral de Burgos, que figura por derecho propio entre los ejemplos más sobresalientes del Renacimiento hispánico. Concebido y realizado por el maestro Felipe Vigarny entre 1499 y 1502, consta en su zona central de tres relieves en piedra de Briviesca con escenas que representan varios momentos de la pasión de Cristo: subida al Calvario, Crucifixión, Ascensión.

En 2013 se inicia un proyecto de investigación con el apoyo del Cabildo de la Catedral y el Banco Santander, en el que participa un amplio equipo de expertos de las Universidades de Valladolid y Zaragoza, el Centro de Conservación y Restauración de Bienes Culturales de Castilla y León y varias empresas, bajo la coordinación de la Dirección General de Patrimonio Cultural.

Uno de los principales problemas detectados fue la presencia y migración de sales en los rellenos que se ubi- 
can entre la parte posterior de los relieves y el retablo mayor de la Catedral, fruto de la reforma efectuada en el presbiterio. Para ello se pone en marcha una de las intervenciones más ambiciosas y complejas de las que se hayan realizado sobre bienes de esta naturaleza. La especialización de los técnicos y la constitución de un equipo interdisciplinar ha sido una de las garantías del éxito. La actuación, con una inversión próxima al millón de euros, está financiada por el Cabildo de la Catedral y la Junta de Castilla y León, con colaboración del Fondo FEDER. Se inició en septiembre de 2018 y concluirá en mayo de 2020.

Otro de los hitos del Camino de Santiago es la basílica de San Isidoro de León, en la que se pueden rastrear los orígenes de la historia de la monarquía leonesa, tanto a través del propio templo como de los restos documentados de la residencia regia y el panteón decorado con las famosas pinturas románicas. Menos conocida es la estancia que se sitúa justamente sobre dicho espacio cementerial, denominada Cámara de Doña Sancha, que a lo largo del tiempo hizo funciones de oratorio, scriptorium y sala capitular. En el s. XVI dicha estancia fue decorada con pinturas murales.

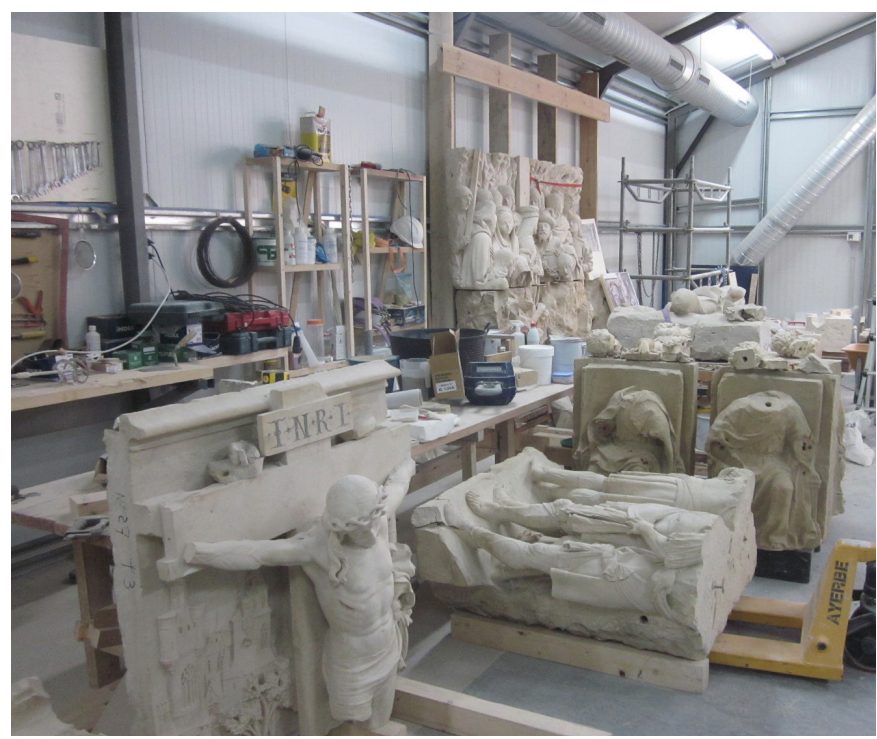

Trasaltar del coro de la Catedral de Burgos. Relieves desmontados en taller de restauración | fotos Dirección General de Patrimonio Cultural de la Junta de Castilla y León, titular de todas las imágenes
Las pinturas fueron arrancadas en los años 60 del pasado siglo en una intervención historicista que pretendía devolver a la sala un aspecto más "medieval". En 2016, después de un estudio exhaustivo, desde la Junta de Castilla y León se plantea la recuperación del conjunto pictórico in situ, además de la reinstalación en su ubicación original de la portada plateresca que daba acceso a la sala.

En el trasaltar de la Catedral de Burgos, paralelamente a la intervención, se ha puesto en marcha un proyecto cultural que busca el acercamiento de la propia restauración al gran público. Está en elaboración un documental que garantice a un tiempo el registro de calidad de esos trabajos y su accesibilidad por parte del conjunto de la sociedad. Y para este 2020 está prevista una exposición temporal sobre el trasaltar, la celebración de un ciclo de conferencias, así como la programación de visitas escolares y talleres didácticos, para los cuales se han reproducido los tres principales relieves del trasaltar a escala $1 / 5$.

Estos son apenas unos botones de muestra de lo que el Camino de Santiago ha significado y sigue significando a su paso por Castilla y León. En torno a él se han levantado monumentos, grandiosos o sencillos. Ha contribuido a modelar paisajes, urbanos o rurales. Ha alentado y sigue alentando el espíritu, el viajero y el estable, el que aspira a permanecer... Todo ello, unido al carácter excepcional que lo hizo merecedor de la protección internacional, al interés que suscitan los elementos patrimoniales que lo jalonan y a su poder vertebrador en el norte de la Península Ibérica y Europa, explica que la administración pública siga permanentemente atenta a su cuidado y mejora. 